\title{
The effect of chemotherapeutic agents on telomere length maintenance in breast cancer cell lines
}

\author{
Azadeh Motevalli · Hemad Yasaei • \\ Sara Anjomani Virmouni · Predrag Slijepcevic • \\ Terry Roberts
}

Received: 11 March 2014/ Accepted: 17 April 2014/Published online: 8 May 2014

(C) The Author(s) 2014. This article is published with open access at Springerlink.com

\begin{abstract}
Mammalian telomeric DNA consists of tandem repeats of the sequence TTAGGG associated with a specialized set of proteins, known collectively as Shelterin. These telosomal proteins protect the ends of chromosomes against end-to-end fusion and degradation. Short telomeres in breast cancer cells confer telomere dysfunction and this can be related to Shelterin proteins and their level of expression in breast cancer cell lines. This study investigates whether expression of Shelterin and Shelterin-associated proteins are altered, and influence the protection and maintenance of telomeres, in breast cancer cells. 5-aza-2'deoxycytidine (5-aza-CdR) and trichostatin A (TSA) were used in an attempt to reactivate the expression of silenced genes. Our studies have shown that Shelterin and Shelterinassociated genes were down-regulated in breast cancer cell lines; this may be due to epigenetic modification of DNA as the promoter region of POT1 was found to be partially methylated. Shelterin genes expression was up-regulated upon treatment of 21NT breast cancer cells with 5-aza-CdR and TSA. The telomere length of treated 21NT cells was measured by q-PCR showed an increase in telomere length at different time points. Our studies have shown that downregulation of Shelterin genes is partially due to methylation in some epithelial breast cancer cell lines. Removal of epigenetic silencing results in up-regulation of Shelterin
\end{abstract}

Electronic supplementary material The online version of this article (doi:10.1007/s10549-014-2975-x) contains supplementary material, which is available to authorized users.

A. Motevalli · H. Yasaei - S. A. Virmouni - P. Slijepcevic ·

T. Roberts $(\square)$

Biosciences, School of Health Sciences \& Social Care,

Brunel University, Uxbridge UB8 3PH, UK

e-mail: Terry.roberts@brunel.ac.uk and Shelterin-associated genes which can then lead to telomere length elongation and stability.

Keywords Shelterin $\cdot$ Telomere $\cdot 5$-aza-CdR $\cdot$ TSA .

Telomerase

\section{Introduction}

Telomeres are made up of G-rich nucleotide repeats of the sequence (TTAGGG) ${ }_{n}$ bound by associated proteins at the ends of the chromosomes of eukaryotic and all mammalian cells $[1,2]$. Telomeric DNA together with the associated telosomal proteins, collectively known as the Shelterin complex, is essential for the overall maintenance of genome integrity and prevents DNA degradation and chromosome end-to-end fusions [3]. The Shelterin or telosome, consist of the six proteins TRF1, TRF2, POT1, TIN2, TPP1 and RAP1, it packages telomeric DNA and helps to hide the chromosome ends from being recognized as sites of DNA damage during DNA replication [4]. TRF1 and TRF2 bind to the double stranded T-loop of telomeric DNA and are implicated in maintaining the formation of the T-loop structure, while POT1 interacts with single-stranded TTAGGG repeats at the $3^{\prime}$ overhang, as well as in the D-loop of the T-loop configuration. TRF1 and TRF2 recruit TIN2, RAP1, TPP1, and POT1 to telomeric DNA [4]. Shelterin proteins interact with a number of other factors known as Shelterinassociated proteins that can influence chromosome end integrity and dynamics. These Shelterin-associated proteins are known as TNKS1, TNKS2, SMG6, and TEP1 [5-7]. Telomerase is a unique cellular ribonucleoprotein (RNP) complex that synthesizes TTAGGG sequence repeats onto the $3^{\prime}$ end of chromosome terminals [1,8]. The core enzyme contains two subunits: telomerase reverse transcriptase 
(TERT) and telomerase RNA (TR) [9]. The TR molecule, complementary to the telomeric repeats, is an important element of the telomerase enzyme; it consists of an RNA template region that facilitates adding telomeric repeats through the action of the reverse transcriptase catalytic subunit of telomerase (TERT) [10]. These two subunits can bind with additional proteins that together expedite synthesis and elongation of telomeric DNA [8]. In the absence of telomerase, i.e., in most normal adult somatic cells, the hexanucleotide repeats decrease after each cell division; therefore cells undergo senescence when the lengths of telomeres are reduced to a critical level. In addition, telomere loss causes genome instability, resulting in destruction of cell-cycle control, one of the hallmarks of cancer [11]. In most cancer cells, telomerase has been reactivated and prevents cancer cells from entering senescence [11]. Consequently, the activation of telomerase is an important step in development of human cancers [7]. In addition, telomere dysfunction through telomere shortening and/or dysregulation of telomeric DNA-binding proteins (Shelterin), occurs in both the in situ and invasive stages of many cancers, such as breast cancer [12]. Previous noteworthy studies reported different expression levels of Shelterin and Shelterin-associated genes in different human cancers [7, 11, 13]. Salhab et al. [7] indicated over-expression of TNKS1, hTERT, EST1, and TEP1 and down-regulation of TNKS2 and POT1 mRNA levels in breast cancer tissues compared with normal breast tissues. Moreover, the lower expression of TRF 1 and $T R F 2$ was found to be associated with the development and progression of breast cancer. However, findings by $\mathrm{Hu}$ et al. [14] in other cancers appeared to be contradictory to this. They demonstrated significant over-expression of TRF1, $T R F 2$, and TIN2 in precancerous lesions, gastric cancer tissues, and lymph node metastases in comparison with normal gastric mucosa tissues [14]. In addition, recently published data by Lu et al. [11], showed over-expression of POT1 mRNA levels in gastric cancer tissues.

Epigenetic modifications such as abnormal DNA methylation and modifications of histones play an important role in cancer development $[15,16]$. In particular, methylation of DNA within promoter regions serves to suppress the expression of genes that could play a critical role in inhibiting tumorigenesis [17, 18]. Histone acetylation and deacetylation catalyzed by the enzymes histone acetyl transferases (HATs) and histone deacetylases (HDACs), respectively, are also important in maintaining the balance between silent and transcriptionally active chromatin. It has been shown that disruption of HATs or HDACs activity can contribute several cancers [19, 20].

In this study, based on the scenario mentioned above, it is hypothesized that down-regulation of Shelterin and Shelterinassociated genes might be under the control of DNA methylation and histone modifications. Therefore, the expression of hypermethylated genes can be actively restored after treatment with DNA methylation inhibitors, such as 5-aza-2' deoxycytidine (5-aza-CdR). In addition, trichostatin A (TSA), a potent inhibitor of mammalian HDAC Class I and II enzymes, can be used to modify gene expression by preventing acetylation of histones within chromatin. For this reason, inhibition of histone acetylation by TSA has been used successfully as an anticancer drug [21,22]. The effect of these drugs on Shelterin and Shelterin-associated genes was investigated in the breast cancer cell line $21 \mathrm{NT}$.

\section{Materials and methods}

Cell culture conditions, reverse transcription, and quantitative real-time PCR

21NT, 21MT-2, and PB1 breast cancer cell lines were grown in modified eagle's alpha (MEM) medium plus $10 \%$ fetal calf serum (FCS), $1 \%$ glutamax, $1 \%$ HEPES, $1 \%$ NEAA, and $1 \mu \mathrm{l} / \mathrm{ml}$ epithelial growth factor (EGF). GI101, BT-20, HS578-T, BT474, MTSV1-7, and MCF-7 cells were cultured in DMEM/F12 containing $10 \%$ FCS and $1 \%$ glutamax, $0.5 \mu \mathrm{g} / \mathrm{ml}$ hydrocortisone whereas HCC1143, LY-R and LY-S were grown in RPMI/1640 plus $10 \%$ FCS and normal mammary epithelial cell strain (LONZA) were grown in MEGM medium with recommended supplements (Table 1). All cell lines were cultured in fully humidified incubators set at $5 \% \mathrm{CO}_{2}$ and $37^{\circ} \mathrm{C}$. RNA was extracted from cells using an RNeasy Mini kit (QIAGEN) and cDNA was synthesized from $1 \mu \mathrm{g}$ total RNA using Superscript reverse transcriptase enzyme (Invitrogen). Quantitative realtime reverse transcriptase PCR (qRT-PCR) was performed on the $7900 \mathrm{HT}$ Fast Real Time PCR machine and $1 \times$ $\mathrm{SYBR}^{\circledR}$ green master mix (Applied Biosystems) that include $5 \mu \mathrm{M}$ primers (Table 2) and $1 \mu \mathrm{l}$ of cDNA.

\section{DNA isolation and methylation-specific PCR}

Genomic DNA was extracted, using the Wizard ${ }^{\mathrm{TM}}$ Genomic DNA Kit and protocol (Promega). Methylcode ${ }^{\mathrm{TM}} \mathrm{Bi}-$ sulphite conversion Kit (Invitrogen) was used for bisulphite treatment of DNA samples. Methylation-specific PCR (MSP) analysis was performed for POT1 using primers (Table 3) specific for methylated and unmethylated DNA products. The MSP products were run on $2 \%$ agarose gels and visualized using ethidium bromide $(0.5 \mu \mathrm{g} / \mathrm{ml})$.

Cell lines, maintenance, treatment, cell viability, and qRT-PCR

To determine the optimal drug dose, $3 \times 10^{5} 21 \mathrm{NT}$ cells were seeded into 6-well plate. Cells that were treated with 
Table 1 Description of different cell lines and normal mammary cell strains (HMECs)

\begin{tabular}{|c|c|c|c|c|c|c|}
\hline Cell lines & $\begin{array}{l}\text { Patient } \\
\text { age }\end{array}$ & $\begin{array}{l}\text { Histopathological } \\
\text { diagnosis }\end{array}$ & $\begin{array}{l}\text { Tumor } \\
\text { stage }\end{array}$ & Primary site & Growth media & References \\
\hline $21 \mathrm{NT}$ & 36 & PDC & Primary & Breast & MEM & {$[35]$} \\
\hline 21MT-2 & 36 & PDC & Metastatic & Breast & MEM & {$[35]$} \\
\hline GI101 & 57 & IDC & III & Breast & $\begin{array}{l}\text { DMEM/F12 without } \\
\text { hydrocortisone }\end{array}$ & - \\
\hline BT-20 & 74 & IDC & - & Breast & $\begin{array}{l}\text { DMEM/F12 without } \\
\text { hydrocortisone }\end{array}$ & [36] \\
\hline HS578-T & 74 & IDC & - & Breast & $\begin{array}{l}\text { DMEM/F12 without } \\
\text { hydrocortisone }\end{array}$ & [37] \\
\hline BT474 & 60 & IDC & - & Breast & $\begin{array}{l}\text { DMEM/F12 without } \\
\text { hydrocortisone }\end{array}$ & {$[38]$} \\
\hline MCF-7 & 69 & IDC & IV & Pleural effusion & $\begin{array}{l}\text { DMEM/F12 without } \\
\text { hydrocortisone }\end{array}$ & [39] \\
\hline HCC1143 & 52 & PDC & II & Breast & RPMI/1640 & [40] \\
\hline MTSV1-7 & - & $\begin{array}{l}\text { Normal immortalized } \\
\text { mammary gland }\end{array}$ & - & Breast & $\begin{array}{l}\text { DMEM/F12 with } \\
\text { hydrocortisone }\end{array}$ & {$[41]$} \\
\hline PB1 & 36 & PDC & Primary & Breast & MEM & {$[35]$} \\
\hline PC3 & 62 & Prostatic adenocarcinoma & IV & Prostate & $\mathrm{F} 12$ & {$[42]$} \\
\hline LY-R & - & $\begin{array}{l}\text { Mouse lymphoma, } \\
\text { radiosensitive }\end{array}$ & - & Lymphoma & RPMI/1640 & $\begin{array}{l}\text { Dr Andrzeg Wojcik } \\
\text { University of Warszawa, } \\
\text { Poland }\end{array}$ \\
\hline LY-S & - & $\begin{array}{l}\text { Mouse lymphoma, normal } \\
\text { radiosensitive }\end{array}$ & - & Lymphoma & RPMI/1640 & $\begin{array}{l}\text { Dr Andrzeg Wojcik } \\
\text { University of Warszawa, } \\
\text { Poland }\end{array}$ \\
\hline HMEC & - & $\begin{array}{l}\text { Normal human mammary } \\
\text { epithelial cell strain }\end{array}$ & - & Breast & MEGM & [43] \\
\hline $\begin{array}{l}\text { Normal } \\
\text { commercial } \\
\text { Tissue }\end{array}$ & 78 & $\begin{array}{c}\text { FirstChoice }{ }^{\circledR} \text { Human } \\
\text { breast total RNA }\end{array}$ & - & Breast & - & $\begin{array}{l}\text { AM6952 (Applied } \\
\text { Biosystems) }\end{array}$ \\
\hline PC3/hTERT & 62 & Prostatic adenocarcinoma & - & $\begin{array}{l}\text { Derived from PC- } \\
3 \text { telomerised }\end{array}$ & $\mathrm{F} 12$ & $\begin{array}{l}\text { Professor Newbold group } \\
\text { (Brunel University) }\end{array}$ \\
\hline
\end{tabular}

$P D C$ primary ductal carcinoma, $I D C$ infiltrating ductal carcinoma

5-aza-CdR (5 $\mu \mathrm{M}$, Sigma, St. Louis, MO) and TSA (Sigma) $(5,15,25,50$, and $100 \mathrm{ng} / \mathrm{ml})$ were stained with Trypan blue (Invitrogen). Stained blue cells were scored as dead cells and unstained bright cells as viable cells. The cell viability was determined by the following formula: No. of viable cell/Total no. of cells $\times 100$. TSA at $50 \mathrm{ng} / \mathrm{ml}$ was judged as being the best concentration to use in all experiment. The $21 \mathrm{NT}$ cell line was plated at a density of $1 \times 10^{5}$ in p100 culture dish, $24 \mathrm{~h}$ after plating; the cells were randomly assigned into treatment and control groups. Treatment included 5-aza-CdR $(5 \mu \mathrm{M})$ for $48 \mathrm{~h}, 72 \mathrm{~h}$, 3 weeks and 2 months, either alone or in combination with TSA $(50 \mathrm{ng} / \mathrm{ml})$. TSA was added only during the last $16 \mathrm{~h}$ of treatment. For control group, one plate was treated with $0.02 \%$ DMSO. The short-term (48 and $72 \mathrm{~h}$ ) and longterm (3 weeks and 2 months) effects of the drugs on the mRNA levels of Shelterin and Shelterin-associated genes were assessed using qRT-PCR in order to compare the difference between each time points of the treatment.
Telomere length measurement by q-PCR

In order to determine telomere length, a real-time PCR technique was used. The relative telomere length was compared with that of the single copy gene (36B4 which encodes the acidic ribosomal phosphoprotein PO) [23]. Genomic DNA was extracted from 21NT-treated cells and the normal human mammary epithelial cell strain (HMEC) using the Wizard ${ }^{\mathrm{TM}}$ Genomic DNA Kit as described previously. $1 \times$ Power SYBER ${ }^{\circledR}$ Green PCR Master Mix (Applied Biosystems), $0.5 \mu \mathrm{M}$ primes with $5 \mathrm{ng} / \mu \mathrm{l}$ sample DNA was used (Table 4).

Stable transfection, qRT-PCR, and western blots analysis

One day prior to transfection, $15 \times 10^{5} 21 \mathrm{NT}$ cells were seeded into p100 tissue culture dishes. Cells were then transfected with the plasmid vector pcDNA-POT1/FRT/ 
Table 2 Shelterin and Shelterin-associated primer sequences for use in real-time PCR

\begin{tabular}{llll}
\hline Primer name & Primer sequence $\left(5^{\prime} \rightarrow 3^{\prime}\right)$ & $\begin{array}{l}\text { Product } \\
\text { length }(\mathrm{bp})\end{array}$ & $\begin{array}{l}\text { Accession } \\
\text { number }\end{array}$ \\
\hline TIN2, $-\mathrm{F}$ & TTCTGGCTGCCATGGAAAAG & 108 & NM_012461 \\
TIN2, $-\mathrm{R}$ & GCTGCATCCAACTCAGCACAT & & \\
TPP1, F & TTAGCGCTGTGTGTGTGCTCTT & 101 & NM_001082486 \\
TPP1, R & CCGAACGGTTCAGCACATATTT & & NR_003102 \\
POT1, -F & GAGAACAAGCGACTATGCCCA & 104 & \\
POT1, $-\mathrm{R}$ & ACCCTAGGAAGAGTTTAGGCGG & & NM_003218 \\
TRF1, -F & ATGCTCGATTTCCTCTGCCTC & 101 & NM_005652 \\
TRF1, -R & CCATGAATAATAGCCTCTGCGC & & NM_018975 \\
TRF2, F & AAAACGAAAGTTCAGCCCCG & 101 & \\
TRF2, R & GCTGTCCTCCTCCAAGACCAAT & & NM_003747 \\
RAP1, F & ACCCTGCTCTTTGGCTGTTCT & 101 & \\
RAP1, R & TGTGTGCGCGTTTTAAGGAA & & N/A \\
TNKS1, F & TCAGTGTCTCTCCCAATGGCAC & 103 & \\
TNKS1, R & TGTTTGCAAGGCCATTTACAGG & & NM_025235 \\
TNKS2, F & CCCAACACTGCTCAATTGTCAC & 101 & \\
TNKS2, R & GCAACGAGTGGCCTTTAAATTC & & \\
TEP1, F & TGCCAGGCCGCACTGTCTTG & 136 & \\
TEP1, R & ACCTGCTCCGCCCTCGTGAT & & \\
SMG6, -F & TCCCAGCAACCCCTTACATCT & 115 & \\
SMG6, -R & AAGCCGGCACAGCTTTTGTAG & & \\
GAPDH-F & GAAGGTGAAGGTCGGAGT & 226 & \\
GAPDH-R & GAAGATGGTGATGGGATTTC & & \\
\hline & & & \\
\hline
\end{tabular}

$F$ foward, $R$ reverse

Table 3 MSP primer sequences of POT1 promoter for PCR products

\begin{tabular}{llll}
\hline Gene/assay & Forward primer $\left(5^{\prime} \rightarrow 3^{\prime}\right)$ & Reverse primer $\left(5^{\prime} \rightarrow 3^{\prime}\right)$ & Product size $(\mathrm{bp})$ \\
\hline POT1-M & AGAAAGGTTTTGTTTATAGGAGT & CCAATAACTTTCCAACTTTCGTA & 118 \\
POT1-U & AAGGTTTTGTTTATAGGAGTTTT & CCCAATAACTTTCCAACTTTCAT & 116 \\
\hline
\end{tabular}

$M$ methylated, $U$ unmethylated

V5-His-TOPO (a kind gift from Roger Reddel) and empty vector (pcDNA3.1/hygro plasmid kindly provided by Dr. Evgeny Makarov) using GeneJuice ${ }^{\circledR}$ Transfection Reagent (Novagen) according to the manufacturer's protocol. This vector contains hygromycin for selection in mammalian cells for stable transfection. POT1 overexpression was quantified using qRT-PCR (mRNA) and western blot (protein) analysis. For western blot analysis, cell pellets were lysed on ice using RIPA (radioimmunoprecipitation assay buffer, Sigma) buffer containing $1 \times$ protease inhibitor (Thermo). Protein concentrations were measured using the Pierce ${ }^{\mathrm{TM}}$ BCA Protein Assay Kit (Thermo Scientific). Samples (prepared in $4 \times$ Laemmle buffer containing $1.5 \mathrm{M}$ Tris-Cl pH 6.8, glycerol, $\beta$-mercaptoethanol, SDS, $1 \%$ bromophenol blue) containing $50 \mu \mathrm{g}$ proteins were separated on a ready-made $12 \%$ precast acrylamide gel (Bio-Rad) and were blotted onto ready-made Mini PVDF transfer membrane (Bio-Rad) using the Trans-Blot ${ }^{\circledR}$ Turbo $^{\mathrm{TM}}$ apparatus (Bio-Rad) according to the manufacturer's protocol. The membrane was hybridized against human POT1 (1:5000, Abcam) and $\beta$-actin (1:10,000, Sigma) antibodies and the signals were detected by ECL plus (enhanced chemiluminescence) kit (GE Healthcare).

Telomerase enzyme activity

All transfected cell pellets were re-suspended in CHAPS lysis buffer (TRAPEZE ${ }^{\circledR} 1 \times$ CHAPS Millipore Company). The protein concentration of samples was determined using the Pierce ${ }^{\mathrm{TM}}$ BCA Protein Assay Kit (Thermo Scientific) according to the manufacturer's protocol. Reaction mixtures for each of the samples to be analyzed were made up using the following components: $1 \times$ standard $^{\mathrm{iTaq}}{ }^{\mathrm{TM}}$ Universal Syber $^{\circledR}$-green (BIO-RAD), $0.05 \mu \mathrm{g} / \mu \mathrm{l}$ of anchored primer (ACX primer) (5'-GCGCGG (CTTACC) 3CTAACC- $3^{\prime}$ ), $0.1 \mu \mathrm{g} / \mu \mathrm{l}$ of telomerase primer (TS Primer) (5'-AATCCGTCGAGCAGAGTT-3'), and $250 \mathrm{ng} / \mu \mathrm{l}$ of protein samples. The reaction mixture was first incubated at 
$25^{\circ} \mathrm{C}$ for $20 \mathrm{~min}$ to allow the telomerase in the protein extracts to elongate to the TS primer by adding TTAGGG repeat sequence. $\mathrm{PCR}$ was then started at $95^{\circ} \mathrm{C}$ for $10 \mathrm{~min}$ to activate Taq polymerase followed by a two-step PCR amplification of 35 cycles at $95^{\circ} \mathrm{C}$ for $30 \mathrm{~s}$ and $60^{\circ} \mathrm{C}$ for $90 \mathrm{~s}$. Telomerase activity is reported as standard cell equivalents. To quantify telomerase activity, a standard curve was generated from serially diluted telomerasepositive prostate cell line; PC-3/hTERT (106-102). All real time amplification was carried out using an ABI Prism 7900HT (Applied Biosystems).

\section{Results}

Expression of Shelterin and Shelterin-associated genes in breast cancer cell lines and normal breast tissue

Maintenance and regulation of chromosome ends, at the telomere is fundamental for genome stability. The relationship between telosomal DNA-binding proteins and telomere length maintenance has become a popular area of interest recently. There have been a limited number of findings looking at the relationship between telomere length and Shelterin genes in breast cancer. Salhab et al. (2008) demonstrated an increase in the mRNA levels of TNKS1, hTERT, EST1, and TEPl in breast cancer tissues whereas TNKS2 and POT1 were down-regulated in comparison with normal breast tissue [7]. Our group reported that POT1, TRF1, TRF2, SMG6, TIN2, TEP1, TNKS2, and $R A P 1$ were significantly down-regulated at the mRNA level in breast cancer cell lines (MCF-7, GI101, BT474, 21MT-2, MTSV1-7, HCC1143, BT20, PB1, HS578-T, and 21NT) a prostate cancer cell line in comparison with RNA extracted from normal mammary breast tissue $(P<0.05$, $P<0.01$ and $P<0.001$ correspondingly) (Fig. 1a-f and Fig. S1). However, interestingly, TPP1 mRNA levels were higher in most breast cancer cell lines compared with normal breast tissue $(P<0.05$ and $P<0.01$ correspondingly) (Fig. 1c).
Detection of DNA methylation of POT1 promoter region in breast cancer cell lines

Several cellular factors (i.e., mutation, DNA methylation, histone acetylation, chromatin remodeling, etc.) in theory could affect the expression of Shelterin and Shelterin-associated genes in breast cancer cell lines. Based on previous published data and our results, POT1 mRNA was found to be significantly down-regulated in malignant breast tissues and cancer cell lines [7]. Moreover, with regard to the hypothesis of a critical role of POT1 in telomere length maintenance [24], this gene was chosen for further investigation. The promoter regions of POT1 gene in breast cancer cell lines were analyzed to investigate whether methylation was responsible for the down-regulation observed. MSP primers were then designed to look for evidence of DNA methylation in the promoter of POT1 in the normal mammary cell strains (HMEC) and the breast cancer cell lines. As evident in Fig. 2a, the POT1 promoter region shows a partial methylation in breast cancer cell lines. MSP showed that the POT1 promoter contains more methylated DNA in 21NT, BT474, 21MT2, and PB1 in comparison with the remainder breast cancer cell lines and HMEC control.

Up-regulation of Shelterin and Shelterin-associated genes by 5 -aza-CdR and TSA

In order to determine the best concentration of TSA to use on $21 \mathrm{NT}$, an optimization experiment was carried out. Cells were treated with TSA between 5 and $100 \mathrm{ng} / \mathrm{ml}$ with $5 \mu \mathrm{M} 5$-aza$\mathrm{CdR}$ for $48 \mathrm{~h}$ and a cell viability assay was carried out to look at cell survival. TSA at $50 \mathrm{ng} / \mathrm{ml}$ with $5 \mu \mathrm{M} 5$-aza-CdR reduced the cell viability to $78 \%$ (Fig. 2b), whereas the lowest percentage of cell survival was observed in cells treated with $100 \mathrm{ng} / \mathrm{ml}$ TSA and $5 \mu \mathrm{M} 5$-aza-CdR (64 \%). Moreover, cells treated with the combination of $50 \mathrm{ng} / \mathrm{ml} \mathrm{TSA}$ and $5 \mu \mathrm{M}$ 5-aza-CdR showed the highest Shelterin expression level (e.g., POT1) among the aforementioned concentrations. Consequently, $50 \mathrm{ng} / \mathrm{ml}$ was judged as being the best concentration to use as it gave the best trade-off between cell

Table 4 Oligomers used for telomere length assay in 21NT-treated and normal cells [23]

\begin{tabular}{llcl}
\hline Oligomer name & Oligomer sequence $\left(5^{\prime} \rightarrow 3^{\prime}\right)$ & $\begin{array}{l}\text { Amplicon } \\
\text { size }(\mathrm{bp})\end{array}$ \\
\hline Telomere standard (human/rodent) & (TTAGGG) ${ }_{14}$ & & 84 \\
36B4 standard (human) & CAGCAAGTGGGAAGGTGTAATCCGTCTCCACAGACAAG & 75 \\
& GCCAGGACTCGTTTGTACCCGTTGATGATAGAATGGG & $>76$ \\
Telo-F (human/rodent) & CGGTTTGTTTGGGTTTGGGTTTGGGTTTGGGTTGGGTT & $>76$ \\
Telo-R (human/rodent) & GGCTTGCCTTACCCTTACCCTTACCCTTACCCTTACCCT & & \\
36B4-F (human) & CAGCAAGTGGGAAGGTGTAATCC & & \\
36B4-R (human) & CCCATTCTATCATCAACGGGTACAA & & \\
\hline
\end{tabular}



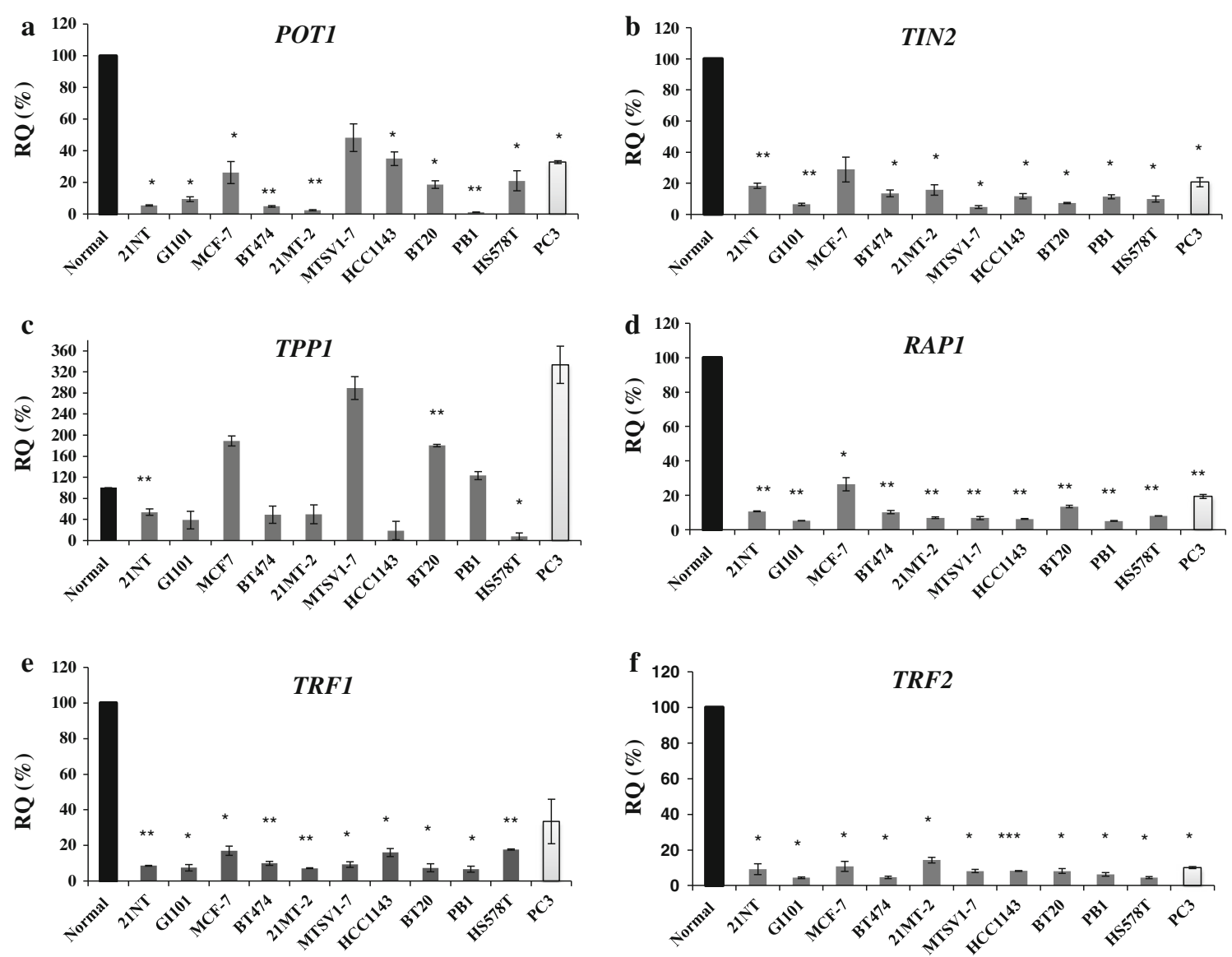

Fig. 1 Expression of Shelterin genes in breast and prostate cancer cell lines. The level of all Shelterin genes normalized against GAPDH mRNA in breast cancer cell lines compared with prostate cancer and normal breast tissue, determined by a quantitative reverse transcription polymerase chain reaction. a-c $P O T 1, T I N 2$, and TPP1 mRNA expression determined by qRT-PCR in breast cancer cell lines, a

normal breast tissue and a prostate cancer cell line (PC-3). $\mathbf{d}-\mathbf{f}$ qRTPCR analysis of RAP1,TRF1, and TRF2 mRNA isolated from cancer cell lines. The PC-3 cell line was included for comparison. Normal breast tissue (cDNA) was used as the calibrator for all graphs. Error bars represent SEM. $* P<0.05, * * P<0.01, * * * P<0.001$

survival and expression (Fig. 2b, c). Treatment of 21NT breast cancer cell lines with $5 \mu \mathrm{M} 5$-aza-CdR and $50 \mathrm{ng} / \mathrm{ml}$ TSA over $48 \mathrm{~h}$, lead to increased expression of $P O T 1$ and TIN2 as compared with the DMSO sample $(P<0.05)$ (Fig. 3a, b). In contrast, the up-regulation of TNKS2, TRF1, $T R F 2$, and $R A P 1$ did not reach the statistical significance (Fig. $\mathrm{S} 2$ ). However, 21NT cells treated solely by TSA did not show up-regulation of TNKS2, TRF2, and RAP1 (Fig. S2). Treatment with 5-aza-CdR alone resulted in up-regulation of all the above genes except TRF1. Indeed, TPP1 after $48 \mathrm{~h}$ of treatment with 5-aza-CdR increased by 4-fold when compared with DMSO and untreated controls $(P<0.05)$ (Fig. 3c).

Effects of prolonged treatment of 21NT cells with 5aza-CdR and TSA on transcription level of POT1 and TIN2

The preliminary results showed significantly increased expression of POT1 and TIN2 mRNA $(P<0.05)$

following 5-aza-CdR and 5-aza-CdR/TSA treatment (Fig. 3a, b). Therefore, we sought to investigate longterm treatment of $21 \mathrm{NT}$ cells to identify whether the expression of these genes may possibly change after longer period of exposure. We examined the expression of POT1 and TIN2 after treatment with $50 \mathrm{ng} / \mathrm{ml}$ TSA and $5 \mu \mathrm{M}$ 5-aza-CdR for $48 \mathrm{~h}, 72 \mathrm{~h}, 3$ weeks, and 2 months in $21 \mathrm{NT}$ cells. The results indicate that treatment of 21NT cells significantly increased transcription levels of POT1 and TIN2 upon treatment with TSA, 5-aza-CdR alone, and in combination with 5-aza-CdR/ TSA after different time points. The result showed that the expression of POT1 and TIN2 after $48 \mathrm{~h}, 72 \mathrm{~h}$, and 3 weeks of treatment with TSA and 5-aza-CdR/TSA was over 4-fold higher than in 21NT untreated cells $(P<0.05, P<0.01$, and $P<0.001$ correspondingly). Nevertheless, up-regulation of POT1 and TIN2 after 2 months treatment did not reach the statistical significance (Fig. 3d, e). 


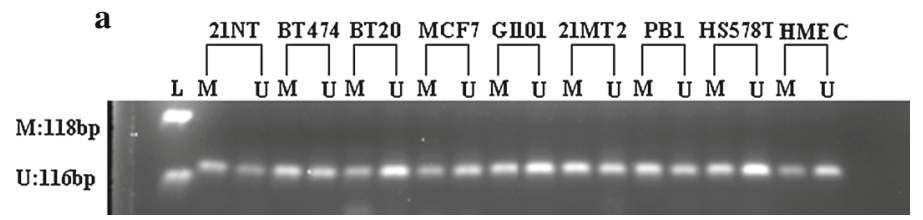

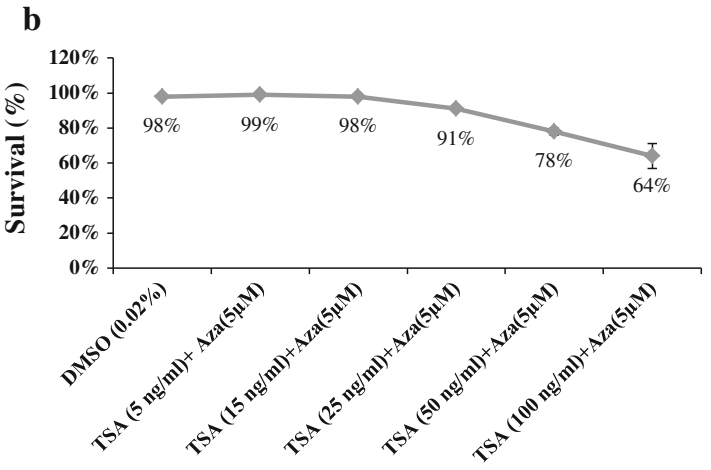

Fig. 2 a Methylation-specific PCR (MSP) analysis of the POT1 promoter in breast cancer cell lines and normal mammary epithelial cell strain (HMEC). POT1 panel viewed from left to right. Lane 1 is the ladder, $M$ presence of methylated DNA, and $U$ unmethylated. b, c The changes in breast cancer cell viability and expression level of POT1 after treatment with TSA and 5-aza-CdR. 21NT cells was

Telomere length measurement by q-PCR following epigenetic changes to the Shelterin genes

To date, no previous investigations have reported on the possible effects of 5-aza-CdR and TSA can have on telomere length maintenance in cancer cells. Hence, the average telomere length was measured by q-PCR in treated and untreated 21NT cells, DMSO-treated (control) at different time points, in order to investigate whether the up-regulation of Shelterin genes such as POT1, TIN2, and TPP1 has an effect on average telomere length. As shown in Fig. $3 \mathrm{f}$ shortterm $(72 \mathrm{~h})$ and 3 weeks treatment of $21 \mathrm{NT}$ cells with 5-aza$\mathrm{CdR}$ showed increase telomere lengths ranging from 4.5 to $4.7 \mathrm{~kb}$ in comparison with untreated and DMSO-treated controls whose telomere lengths were around $2 \mathrm{~kb}$. The mean telomere length of the combination treatment of $21 \mathrm{NT}$ cells with 5-aza-CdR and TSA for $72 \mathrm{~h}$ and 3 weeks had a significant telomere length increase (Fig. 3f) to about 3.4 and $3.7 \mathrm{~kb}$, respectively $(P<0.05)$. BT474 and MCF7, which also had partial methylation of the $P O T 1$ promoter, were then treated as above for $72 \mathrm{~h}$. Both cell lines also showed an increase in telomere length (Fig. S3) therefore confirming that this is a common occurrence following treatment with 5-aza-CdR and TSA. To our surprise, treatment of HMEC with 5-aza-CdR and TSA resulted in a substantial increase in telomere length. This observation is consistent with recent report showing that treatment of cloned blastocysts and pigs by TSA resulted in telomere length elongation [25]. In addition, Blasco and her group reported that mouse

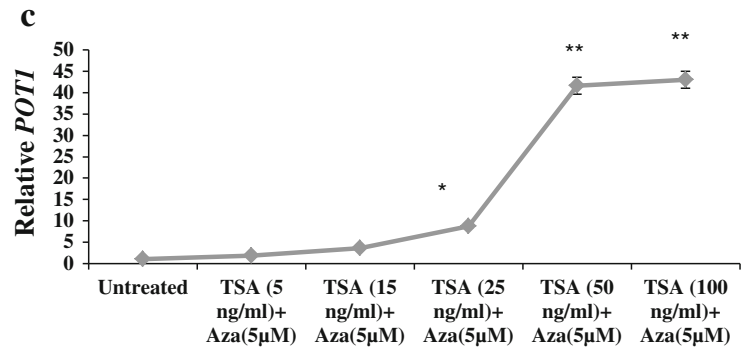

treated with TSA at different concentration and with a single concentration $(5 \mu \mathrm{M})$ of 5 -aza-CdR. The cell viability assay was performed to determine cell survival. qRT-PCR results show changes in POT1 expression levels in $21 \mathrm{NT}$ cells after treatment with TSA at different concentrations and 5-aza-CdR for $48 \mathrm{~h}$

embryonic stem cells genetically deficient in DNA methyltransferases at subtelomeric regions resulted in dramatically elongated telomere length [26].

Over-expression of POT1 facilitates telomere length elongation in $21 \mathrm{NT}$ cells

Our data may suggest that the regulation of the Shelterin protein complex is needed to maintain telomere length regulation in breast cancer cell lines. Previous studies showed that reduction of $P O T I$ by RNAi results the loss of the $3^{\prime}$ overhangs [27]. Furthermore, it had also been observed that over-expression of $\mathrm{POTl}$ in telomerase-positive cells resulted in telomere length elongation [24, 28].

In order to evaluate the effects of POTl (variation 1, full length) over-expression in $21 \mathrm{NT}$ cancer cells, these cells were transfected with human POTI. As shown in Fig. 4a, POT1 mRNA levels were elevated 3- to 4-fold in the POT1-1/pcDNA5 and POT1-3/pcDNA5 clones compared with non-transfected 21NT cells and empty vector controls. This difference was statistically significance when compared with the level in non-transfected 21NT cells $(P<0.5)$. Western blot analysis confirmed overexpression of POT1 in transfected 21NT cells at the protein level (Fig. 4b). In order to obtain a better and clear understanding of the exact role and function of POT1 in protection and maintenance of telomeres in human breast cancer, we needed to determine whether overexpression of 

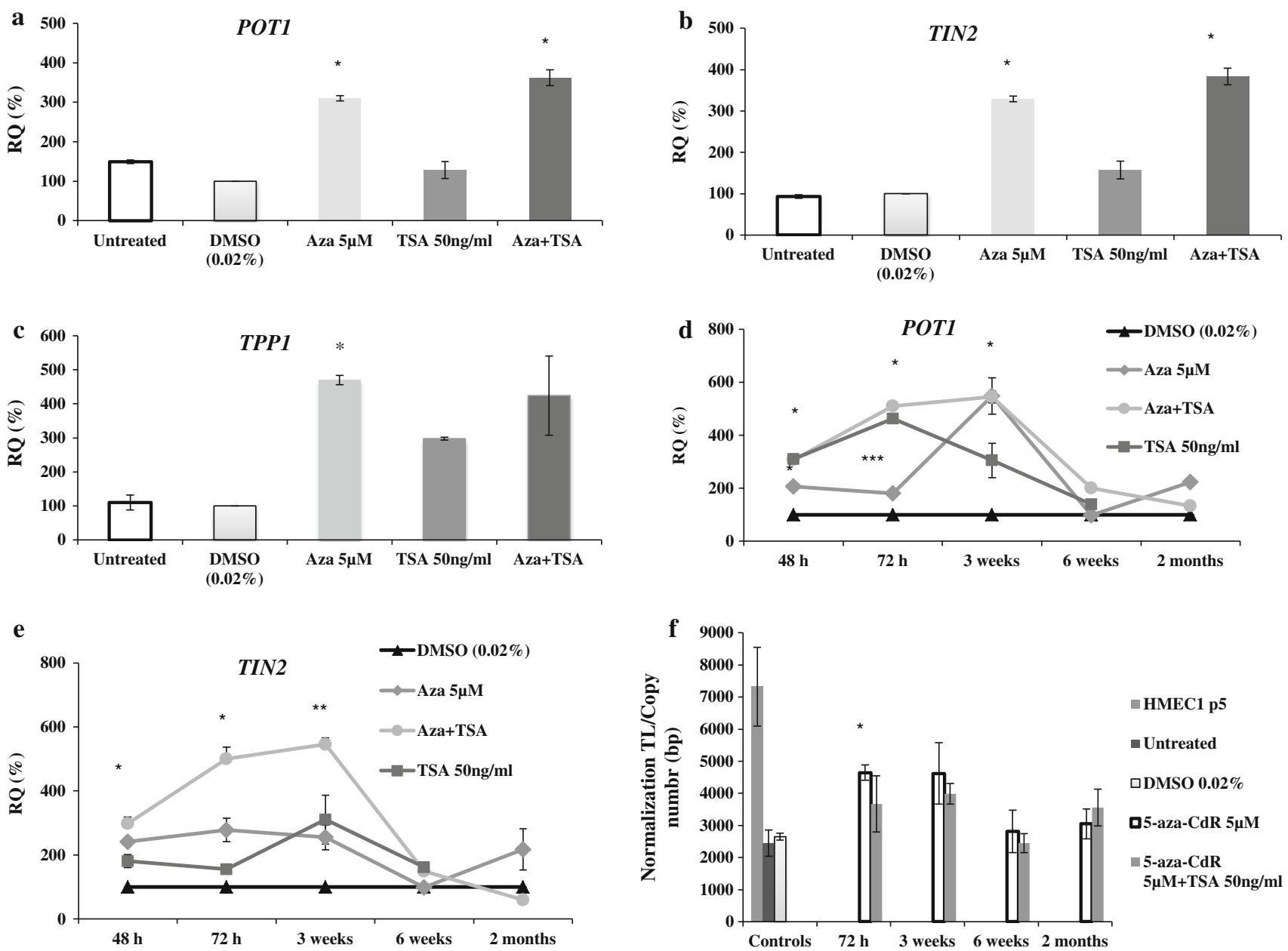

Fig. 3 Effects of 5-aza-CdR and TSA on the expression of POT1, $T I N 2$, and TPP1 in the $21 \mathrm{NT}$ breast cancer cell line. a-c qRT-PCR analysis of POT1, TIN2, and TPP1 mRNA levels following 5-aza$\mathrm{CdR}$ and TSA treatments in 21NT cells for $48 \mathrm{~h}$. Expression of each gene was normalized to GAPDH mRNA level. DMSO control was used as the calibrator. $R Q$ and error bars indicate relative quantification and SEM. Asterisk indicates significant difference between 21NT-treated cells and DMSO control $(* P<0.05)$. d, e Expression of POT1 and TIN2 in 21NT-treated cells at different time points. The graph represents analysis of mRNA from the indicated 21NT-treated

POT1 may play a role in telomere length maintenance. For this analysis, the q-PCR technique was used. The average telomere length of 21NT non-transfected and empty vector control clones ranged from 2.5 to $3 \mathrm{~kb}$, while the POT1 over-expressing clones were between 4 and $5 \mathrm{~kb}$. This represents an increase in telomere length of approximately $2 \mathrm{~kb}$ around 4 weeks after transfection (Fig. 4c). Telomerase activity within stable clones was measured in order to search for a link between telomerase activity and increased telomere elongation. The results presented in Fig. 4d, show that approximately 2 -fold reduction in telomerase enzyme activity was observed in two stable clones compared with 21NT cells, non-transfected, and PC-3/hTERT controls.

cells by qRT-PCR. DMSO-treated (control) was used as the calibrator. Error bars represent SEM. Asterisk indicates significant differences between 21NT-treated cell lines and DMSO control $(* P<0.05, * * * P<0.001$, and $* * P<0.01)$. f Effects of 5 -aza-CdR and TSA on telomere length. The analysis was performed with untreated and DMSO-treated 21NT being used as controls, these were compared with $21 \mathrm{NT}$ treated at different time points. HMEC, p5 was used as positive control. Error bars represent SEM. Asterisk indicates difference between DMSO-treated cells and 21NT-treated cell lines $(* P<0.05)$

Our data suggested that telomere elongation by POT1 is not mediated by increased telomerase enzyme activity.

\section{Discussion}

Here, we have provided evidence that using inhibitors of methyltransferases (5-aza-CdR) has the potential to cause telomere elongation. The National Cancer Institute database reported that these epigenetic modification agents have been used as anti-cancer drugs in about 100 clinical trials [29]. The drugs have been used to treat different types of leukemia, sickle cell anemia, and $\beta$-thalassemia [30]. It 

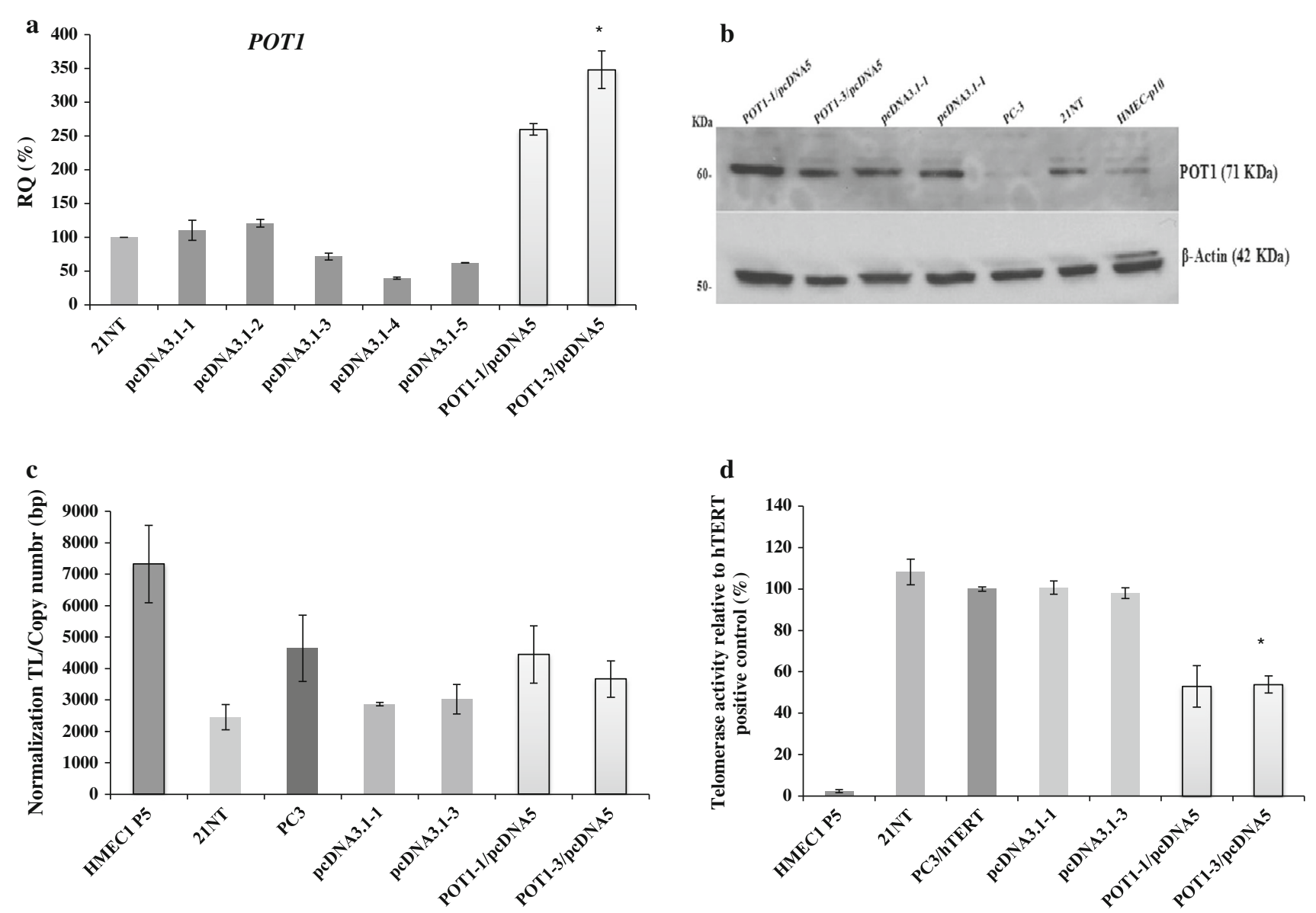

Fig. 4 a Over-expression of POT1 (variation 1) after transfection of 21 NT cells. Data shows the average expression level of POT1 in $21 \mathrm{NT}$ non-transfected control, five vector control clones and two clones after POT1 transfection, relative to GAPDH. The nontransfected $21 \mathrm{NT}$ cells were used as the calibrator. $R Q$ indicates relative quantification and error bars represent SEM. Asterisk indicates significant difference between $21 \mathrm{NT}$ cells and transfected cells $(* P<0.05)$. b Western blots analysis of POT1 in $21 \mathrm{NT}$ transfected and control cell. A $12 \%$ SDS-PAGE gel showing POT1 protein expression in transfected $21 \mathrm{NT}$ cells, two empty vector controls, PC-3, non-transfected 21NT and normal mammary epithelial cell strain (HMEC-p10). $\beta$-Actin was used as a loading control.

has been shown that 5-aza-cdR has a global effect on gene expression in acute myeloid leukemia [31] therefore we can assume that 5-aza-CdR has a global effect on the expression of Shelterin and Shelterin-associated genes as well as DNA methyltransferases enzymes [29]. Our study has shown that in breast cancer, Shelterin expression can be down-regulated through epigenetic modification of DNA and histone proteins. Results obtained have shown that the use of chemotherapeutic epigenetic modifying drugs, such as 5-aza-CdR and TSA, induce and increase the expression of several Shelterin and Shelterin-associated genes in breast cancer cell lines. Up-regulation of these genes ultimately leads to an increase in telomere length. The effect of 5-aza-CdR and TSA on mammalian telomeres has not

c Telomere length in $21 \mathrm{NT}$ transfected and control cell lines by q-PCR. Analysis was performed with non-transfected 21NT, two vector control clones, two stable clones, and HMEC1 p5 and PC-3 controls. Error bars represent SEM. d Quantitative telomerase activity. All values were acquired based on $C_{\mathrm{T}}$ values. Relative telomerase enzyme activity was obtained utilizing a standard curve generated by the serial dilution of PC-3/hTERT. The analysis was performed with the highest telomerase enzyme activity assigned to the PC-3/hTERT sample and the activity in the unknown worked out as a percentage of the PC-3/hTERT sample. Error bars represent SEM. Asterisk indicates significant difference between 21NT cells and transfected cells $(* P<0.05)$

been widely reported in the literature to date making the results presented here novel. We can now speculate on how the use of therapeutic agents such as 5-aza-CdR and TSA to increase telomere lengths of cancer cells may benefit clinical outcome. Research into the role of Shelterin and telomerase in cancer has found that telomerase re-activation functions to maintain telomeres at a critically short length [32]. Telomeres in this unstable state are still prone to genetic damage via end-to-end fusions and translocations. This will have the effect of damaging the genome of the cancer cell giving rise to further clonal evolution and a more advanced disease. If drugs such as 5 -aza-CdR and TSA are used to treat cancer, they could induce telomere lengthening. This may have the effect of stabilizing the 
telomere and reducing the amount of genetic damage the cell will undergo thereby stopping the clonal evolution of the cancer cell population. These tumors may be more susceptible to further treatment as a result. Alternatively, lengthening the telomeres of cancer cells may give rise to chemo-resistant tumors. In our study, HMEC also showed an increase in telomere lengths upon treatment with 5-azaCdR and TSA, this was unexpected as these cells already have long telomeres. HMEC's are known to have residual telomerase activity [33], this together with the added drugs could be responsible for the telomere elongation observed in these cells. Targeting Shelterin protein components may be more effective that targeting telomerase [45], especially POT1 which is implicated to regulate telomere length and capping [4, 34]. We found that telomere elongation by over-expression of $P O T 1$ was not due to a direct effect of increased telomerase activity. Colgin et al. (2003) also observed this when they over-expressed POT1 in telomerase-positive cells, hence it seems likely that POT1 negatively regulates telomerase activity [24, 28, 44]. In conclusion, our results indicated that most of the Shelterin and Shelterin-associated genes were significantly downregulated at the mRNA level in breast cancer cell lines. Further investigations showed that the promoter region of POT1 was partially methylated in breast cancer cell lines. We observed that 5-aza-CdR and TSA treatment of HMEC, $21 \mathrm{NT}, \mathrm{Bt} 474$, and MCF7 lead to an increase in telomere lengths when compared to untreated controls.

Acknowledgments We are indebted to Professor Robert Newbold for useful discussion and for providing the facilities to carry out this work. We would also like to thank Alison Marriott for technical advice on growing the cell lines. The POT1 cDNA was cloned into the plasmid vector pcDNA-FRT/V5-His-TOPO which was kindly provided by Roger R. Reddel (Children's medical Research Institute, Australia).

Conflict of interest The authors declare no conflict of interest.

Open Access This article is distributed under the terms of the Creative Commons Attribution Noncommercial License which permits any noncommercial use, distribution, and reproduction in any medium, provided the original author(s) and the source are credited.

\section{References}

1. Griffith JD, Comeau L et al (1999) Mammalian telomeres end in a large duplex loop. Cell 97(4):503-514

2. Smogorzewska A, de Lange T (2004) Regulation of telomerase by telomeric proteins. Annu Rev Biochem 73:177-208

3. Palm W, de Lange T (2008) How shelterin protects mammalian telomeres. Annu Rev Genet 42:301-334

4. Martinez P, Blasco MA (2010) Role of shelterin in cancer and aging. Aging Cell 9(5):653-666
5. Smith S, Giriat I et al (1998) Tankyrase, a poly(ADP-ribose) polymerase at human telomeres. Science 282(5393):1484-1487

6. Liu Y, Snow BE et al (2000) Telomerase-associated protein TEP1 is not essential for telomerase activity or telomere length maintenance in vivo. Mol Cell Biol 20(21):8178-8184

7. Salhab M, Jiang WG et al (2008) The expression of gene transcripts of telomere-associated genes in human breast cancer: correlation with clinico-pathological parameters and clinical outcome. Breast Cancer Res Treat 109(1):35-46

8. Wyatt HD, West SC et al (2010) InTERTpreting telomerase structure and function. Nucleic Acids Res 38(17):5609-5622

9. Meyerson M, Counter CM et al (1997) hEST2, the putative human telomerase catalytic subunit gene, is up-regulated in tumor cells and during immortalization. Cell 90(4):785-795

10. Autexier C, Lue NF (2006) The structure and function of telomerase reverse transcriptase. Annu Rev Biochem 75:493-517

11. Lu L, Zhang C et al (2011) Telomerase expression and telomere length in breast cancer and their associations with adjuvant treatment and disease outcome. Breast Cancer Res 13(3):R56

12. Butler KS, Hines WC et al (2012) Coordinate regulation between expression levels of telomere-binding proteins and telomere length in breast carcinomas. Cancer Med 1(2):165-175

13. Cookson JC, Laughton CA (2009) The levels of telomere-binding proteins in human tumours and therapeutic implications. Eur $\mathbf{J}$ Cancer 45(4):536-550

14. Hu H, Zhang Y et al (2010) Expression of TRF1, TRF2, TIN2, TERT, KU70, and BRCA1 proteins is associated with telomere shortening and may contribute to multistage carcinogenesis of gastric cancer. J Cancer Res Clin Oncol 136(9):1407-1414

15. Lund AH, van Lohuizen M (2004) Epigenetics and cancer. Genes Dev 18(19):2315-2335

16. Kouzarides T (2007) Chromatin modifications and their function. Cell 128(4):693-705

17. Das PM, Singal R (2004) DNA methylation and cancer. J Clin Oncol 22(22):4632-4642

18. Mossman D, Kim KT et al (2010) Demethylation by 5-aza-2'deoxycytidine in colorectal cancer cells targets genomic DNA whilst promoter $\mathrm{CpG}$ island methylation persists. BMC Cancer 10:366

19. Bannister AJ, Kouzarides T (2011) Regulation of chromatin by histone modifications. Cell Res 21(3):381-395

20. Zhang F, Li Y, Qin G (2008) Effects of trichostatin A (TSA) on growth and gene expression in HeLa cells. J Clin Oncol 7(5):304-308

21. Drummond DC, Noble CO et al (2005) Clinical development of histone deacetylase inhibitors as anticancer agents. Annu Rev Pharmacol Toxicol 45:495-528

22. Meng CF, Dai DQ et al (2008) Effects of 5-Aza-2'-deoxycytidine and trichostatin $\mathrm{A}$ on DNA methylation and expression of hMLH1 in ovarian cancer cell line COC1/DDP. Ai Zheng 27(12):1251-1255

23. O'Callaghan NJ, Fenech M (2011) A quantitative PCR method for measuring absolute telomere length. Biol Proc Online 13:3

24. Yang Q, Zhang R et al (2007) Functional diversity of human protection of telomeres 1 isoforms in telomere protection and cellular senescence. Cancer Res 67(24):11677-11686

25. Kong Q, Ji G, et al (2014) Telomere elongation facilitated by trichostatin A in cloned embryos and pigs by somatic cell nuclear transfer. Stem Cell Rev 10(3):399-407

26. Susana G, Isabel J et al (2006) DNA methyltransferases control telomere length and telomere recombination in mammalian cells. Nat cell Biol 8(4):416-424

27. Yang Q, Zheng YL et al (2005) POT1 and TRF2 cooperate to maintain telomeric integrity. Mol Cell Biol 25(3):1070-1080

28. Colgin LM, Baran K et al (2003) Human POT1 facilitates telomere elongation by telomerase. Curr Biol 13(11):942-946 
29. Ghoshal K, Datta J et al (2005) 5-Aza-deoxycytidine induces selective degradation of DNA methyltransferase 1 by a proteasomal pathway that requires the KEN box, bromo-adjacent homology domain, and nuclear localization signal. Mol Cell Biol 25(11):4727-4741

30. Saunthararajah Y, Hillery CA et al (2003) Effects of 5-aza- $2^{\prime}$ deoxycytidine on fetal hemoglobin levels, red cell adhesion, and hematopoietic differentiation in patients with sickle cell disease. Blood 102(12):3865-3870

31. Schmelz K, Sattler N et al (2005) Induction of gene expression by 5-Aza-2'deoxycytidine in acute myeloid leukemia (AML) and myelodysplastic syndrome (MDS) but not epithelial cells by DNA-methylation-dependent and -independent mechanisms. Leukemia 19(1):103-111

32. Low KC, Tergaonkar V (2013) Telomerase: central regulator of all of the hallmarks of cancer. Trends Biochem Sci 38(9):426-434

33. Sputova K, Garbe JC et al (2013) Aging phenotypes in cultured normal human mammary epithelial cells are correlated with decreased telomerase activity independent of telomere length. Genome Integr 4(4):1-8. doi:10.1186/2041-9414-4-4

34. Lu Y, Wei B et al (2013) How will telomeric complex be further contributed to our longevity? - the potential novel biomarkers of telomere complex counteracting both aging and cancer. Protein Cell 4(8):573-581

35. Band V, Zajchowski D et al (1990) Tumor progression in four mammary epithelial cell lines derived from the same patient. Cancer Res 50(22):7351-7357

36. Lasfargues EY, Ozzello L (1958) Cultivation of human breast carcinomas. J Natl Cancer Inst 21(6):1131-1147
37. Hackett AJ, Smith HS et al (1977) Two syngeneic cell lines from human breast tissue: the aneuploid mammary epithelial (Hs578T) and the diploid myoepithelial (Hs578Bst) cell lines. J Natl Cancer Inst 58(6): 1795-1806

38. Lasfargues EY, Coutinho WG et al (1978) Isolation of two human tumor epithelial cell lines from solid breast carcinomas. J Natl Cancer Inst 61(4):967-978

39. Soule HD, Vazguez J et al (1973) A human cell line from a pleural effusion derived from a breast carcinoma. J Natl Cancer Inst 51(5):1409-1416

40. Gazdar AF, Kurvari V et al (1998) Characterization of paired tumor and non-tumor cell lines established from patients with breast cancer. Int J Cancer 78(6):766-774

41. D’Souza B, Berdichevsky F et al (1993) Collagen-induced morphogenesis and expression of the alpha 2-integrin subunit is inhibited in c-erbB2-transfected human mammary epithelial cells. Oncogene 8(7):1797-1806

42. Kaighn ME, Narayan KS et al (1979) Establishment and characterization of a human prostatic carcinoma cell line (PC-3). Invest Urol 17(1):16-23

43. Garbe JC, Bhattacharya S et al (2009) Molecular distinctions between stasis and telomere attrition senescence barriers shown by long-term culture of normal human mammary epithelial cells. Cancer Res 69(19):7557-7568

44. Wang F, Podell ER et al (2007) The POT1-TPP1 telomere complex is a telomerase processivity factor. Nature 445(7127):506-510

45. Holysz H, Lipinska $\mathrm{N}$ et al (2013) Telomerase as a useful target in cancer fighting-the breast cancer case. Tumour Biol 34(3):1371-1380 